\title{
PREDICTING FUTURE CRYPTOCURRENCY INVESTMENT TRENDS BY CONJOINT ANALYSIS
}

\author{
DOI: 10.17261/Pressacademia.2018.999 \\ JEFA- V.5-ISS.4-2018(1)-p.321-330
}

\author{
Nurgun Komsuoglu Yilmaz ${ }^{1}$, Hulya Boydas Hazar² \\ ${ }^{1}$ Istanbul Aydin University, Department of Business Administration, Besyol, Sefakoy, Istanbul, Turkey. \\ nurgunyilmaz@aydin.edu.tr, ORCID: 0000-0002-9050-9796 \\ 2 Istanbul Aydin University, Department of Business Administration, Besyol, Sefakoy, Istanbul, Turkey. \\ hulyahazar@aydin.edu.tr, ORCID: 0000-0002-7115-1899
}

Date Received: October 15, 2018

Date Accepted: December 25, 2018

To cite this document

Yilmaz, K. N., Hazar, B. H. (2018). Predicting future cryptocurrency investment trends by conjoint analysis. Journal of Economics, Finance and Accounting (JEFA), V.5(4), p.321-330

Permemant link to this document: http://doi.org/10.17261/Pressacademia.2018.999

Copyright: Published by PressAcademia and limited licenced re-use rights only.

\section{ABSTRACT}

Purpose- Trade goods have been used as exchange mediums since the first humans. A thousand years ago currency was invented, and it became the dominant exchange medium in today's world. The history of money did not end with the invention of fiat currency, such as US Dollar or Euro. Cryptocurrency is the new development. It is not a trade good, nor a fiat money. "It is a new, experimental kind of money." In this study our purpose is to analyze the factors influencing investors' decision making on investment in cryptocurrencies by using conjoint analysis. Studies suggest that some attributes of cryptocurrencies affect decisions of investors. In this study, the attributes at different levels related to investors' expectations on cryptocurrencies are examined.

Methodology- In this study, conjoint analysis has been conducted. Conjoint method is a statistical analysis method and by using this method researchers determine the value of the attributes of a product or a feature for its consumers. Conjoint analysis is a method for analyzing preferences of customers; it is a useful tool for predicting and determining responses of customers to new product features and totally new products. In this case customers are investors and the new product is cryptocurrencies. Conjoint analysis has several types, choice based conjoint analysis is one of them and it is the preferred method for most of the researchers.

Findings- Data collected for the study has been analyzed by using Marketing Engineering for Excel software. The findings of the study indicate that profitability, bookkeeping and security are the most important attributes which influence expectations of investors in cryptocurrencies. Five attributes with five levels each are chosen. It is predicted that these attributes are the most important indicators of investor behavior. According to research findings, most important attribute for investors is profitability. This study confirms that the majority of investors have high profit expectation from crypto currencies. But study results also include some unexpected findings. Anonymity is not one of the main concerns for investors and almost equal number of investors prefers very high and very low level of bookkeeping.

Conclusion- The conjoint analysis gives a clear view on what investors expect from cryptocurrencies. The results show the attributes to improve when developing a cryptocurrency.

Keywords: Bitcoin, cryptocurrency, investment, investor expectations, conjoint analysis.

JEL Codes: G11, G19, G23

\section{INTRODUCTION}

In this study, the factors influencing investors' decision-making process on cryptocurrencies are examined by using conjoint analysis. As it is seen in the related literature, studies suggest that some attributes of investments affect decisions of investors. Attributes and the levels of them are determined and data collected from samples by using conjoint cards. Findings of the study indicate that most important attributes for investors in their decision-making process are profitability, anonymity and convenience.

Cryptocurrencies are digital financial assets which uses cryptography. These coins with real monetary value are traded in virtual environments. Bitcoin, the first crypto currency, has been traded in international markets since 2009. After Bitcoin, over 1,500 alternative crypto currencies have taken place in the market. These alternative currencies are also called altcoins. Mainstream altcoins are Ethereum, Litecoin etc. However, it is a niche market now and in the long run cryptocurrencies are considered to be a substitute for national currencies. 
Blockchain technology has been used in creating cryptocurrencies. Simply blockchain technology is a record list. These records are named as blocks and these blocks are interlinked one by one by using cryptographic methods. Both bitcoin and altcoins use blockchain technology in their design.

In this research it is examined cryptocurrencies to determine their attributes which has an effect on investor decision making process. Five factors chosen for this study are profitability, convenience, anonymity, security and bookkeeping. For each of these attributes, attribute levels have been determined. By using conjoint analysis, these attributes and their levels have been analyzed.

\section{LITERATURE REVIEW}

\subsection{Defining Cryptocurrencies}

Trade goods have been used as exchange mediums since the first humans. A thousand years ago currency was invented, and it became the dominant exchange medium in today's world. The history of money did not end with the invention of fiat currency, such as US Dollar or Euro. Cryptocurrency is the new development. It is not a trade good, nor a fiat money. "It is a new, experimental kind of money." (Dourado \& Brito, 2014).

A cryptocurrency is considered as an asset which digitally uses strong cryptography. It is constructed to function as a medium of exchange. Its creation is controlled by the network in which it operates, to secure the transactional flow, as well as to control the creation of additional units of the currency. (Chohan, 2017, Wikipedia, 2018). Cryptocurrencies, like Bitcoin and the other similar altcoins, use blockchain protocols. Blockchain platform provides a mechanism for a distributed network consisted of computational nodes to periodically agree on a set of new transactions and the interest for the protocol signifies its attributes like security, anonymity and data integrity. (Yli-Huumo, Ko, Choi, Park, \& Smolander, 2016).

Cryptocurrencies have a complex nature. They have many attributes to discover. The complex structure of cryptocurrencies has not been fully investigated yet (Phillip, Chan, \& Peiris, 2018). Decentralization is one of the key features of cryptocurrencies. The birth of Bitcoin not only led to a new digitalization movement in the payments sector, but also a new type of innovative technology based on decentralized digital currencies (Glaser \& Bezzenberger, 2015). One other key feature of cryptocurrencies is immutability. Immutability (Puthal, Malik, Mohanty, Kougianos, \& Das, 2018) means that transactions are immutable (unchangeable) and public. Trustless is one other key factor and it symbolizes that none of the players in the blockchain must trust anyone or any authority in order for the network to function.

\subsection{Types of Cryptocurrencies}

Bitcoin was launched in 2009 and has been the market leader since. It is a purely peer-to-peer version of electronic cash which would allow online payments to be sent directly from one party to another without going through a financial institution (Nakamoto, 2008). It is considered as the first cryptocurrency which uses the blockchain technology. After bitcoin, many types of altcoins and crypto-tokens were created. Some of them survived to date.

Bitcoin runs on a decentralized open-source network. Attributes of the network seem disruptive, yet these attributes are the cause of its popularity (Sompolinsky \& Zohar, 2013). Bitcoin is considered to be the most successful cryptographic currency in history. Total value of existing bitcoins reached billions of dollars within two years of its launch in 2009 despite all of its faults in its system design (Bonneau et al., 2015).

After Bitcoin's launch in 2009, many alternative types of cryptocurrencies aka altcoins have emerged in the market. With all these types of altcoins claiming to offer many different and distinctive features to investors, it is becoming increasingly hard for investors to assess the potential of each altcoin (Ong, Lee, Li, \& Chuen, 2015). The word altcoin refers all cryptocurrencies other than bitcoin. And the term altcoin stands for alternative coin or alternative to bitcoin. Bitcoin is the market leader because it is the first one to be widely traded not because it emerged after competing with others. With so many cryptocurrencies in the market, some of them are catching up the popularity of bitcoin (Iwamura, Kitamura, \& Matsumoto, 2014).

The cryptocurrency market showed a steady growth and was over $\$ 100$ billion market capitalization by June 2017. This marks an increasing importance of cryptocurrencies to the financial world. Bitcoin and altcoins compete to increase their market share. Between March 2013 and December 2014, the market value of Bitcoin increased four times and altcoins twelve times. Meanwhile, Bitcoin's market share reduced from $95 \%$ to $84 \%$ (White, 2015). Current market share of Bitcoin is about $47.6 \%$ and descending. This means that the total market share of altcoins is more than $50 \%$ in 2018 . Since the market of altcoins is increasing rapidly, it is possible to say that in the near future Bitcoin will not dominate the whole cryptocurrency market.

Some mainstream altcoins are described as follows: 
- Ethereum: Ethereum is the second most popular platform among cryptocurrencies. It is created by Joseph Lubin. Its strength comes from the fact that it is possible to write application programs which runs on the Ether network. Therefore, the possibility of using the platform to program for all the needs is infinite. According to hacked.com (2018) Ethereum may lead the cryptocurrency market and get more market share than Bitcoin in near future. With its 21 billion $\$$ market cap Ethereum is the $2^{\text {nd }}$ largest coin in the market.

- $\quad$ Ripple: Ripple can be considered as a cryptocurrency and a digital payment system. It is introduced in 2012 by Chris Larsen, a technology entrepreneur. XRP, Ripple's currency component, has mathematical modeling very

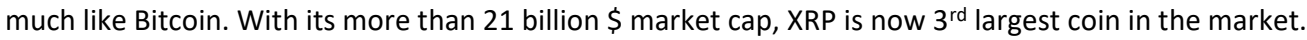

- Bitcoin Cash: Bitcoin Cash, as a sub-currency of bitcoin has more than 10 billion $\$$ market cap and is in the $4^{\text {th }}$ place in the market.

- Stellar: Stellar defines itself as a platform that connects banks, payments systems, and people (Stellar.org, 2018). Stellar is a crypto currency based on the protocol of Ripple. Other than Ripple, Stellar's goal is being in developing markets and other well-shaped financial structures (Stellar News, 2018). With its more than 5 billion \$ market cap, Stellar is now $5^{\text {rd }}$ largest coin in the market.

- EOS: EOS is a blockchain platform for the development of decentralized applications, like Ethereum in function (What is EOS, 2018). With its more than 5.1 billion $\$$ market cap, EOS is now $6^{\text {th }}$ largest coin in the market.

- Litecoin: Litecoin seems to be one of the leading competitors of Bitcoin. A lot of computer power is required for Bitcoin mining. On the other hand, Litecoin can be etched with a normal desktop computer. With its more than 3 billion $\$$ market cap, Litecoin is now $7^{\text {th }}$ largest coin in the market.

- Mintchip: MintChip is the Canada's cryptocurrency and is created by a government agency. It is supported by Canadian dollars. This situation is highly unusual for a cryptocurrency. Cryptocurrencies are decentralized digital currencies, i.e. they are not backed nor regulated by any authority.

Most studies are focused on Bitcoin and a few others. The system as a whole has not been comprehensively analyzed (Elbahrawy, Alessandretti, Kandler, Pastor-Satorras, \& Baronchelli, 2017). For most types of cryptocurrencies there are no studies in literature. Some preliminary studies covers Ethereum (Atzei, Bartoletti, \& Cimoli, 2017; Aung \& Tantidham, 2018; Buterin, 2014; Corbet, Lucey, \& Yarovaya, 2018; lansiti et al., 2017; Pustišek \& Kos, 2018; Wood, 2014) and a few studies on Ripple (Leising \& Robinson, 2018; Schwartz, Youngs, \& Britto, 2014). These studies are mostly focusing on the cryptocurrencies' technical structure.

\subsection{Investing in Cryptocurrencies}

Investors' attention is shifting towards cryptocurrencies and many investors started to include such currencies in their portfolios. As a result, cryptocurrencies are the new investment instruments (Lee, Guo, \& Wang, 2018). They are virtual alternative assets for investors' portfolio which are not regulated by authorities (Jiang \& Liang, 2016). Not being regulated by authorities sometimes mean that these investment alternatives are less vulnerable against financial crises.

Despite their increased popularity, many features and theoretical foundations of cryptocurrencies are not comprehensively understood by the investors (Chohan, 2017). Therefore, many investors shy away even though there is an appetite for cryptocurrency investment. Investments in this area are expected to grow as common knowledge increases in such coins. People's interest in them increases day by day. Many people want to become a cryptocurrency investor. These investors can be categorized into two main categories: miners and traders.

- Miners run algorithms using computers and sometimes use specialized devices to find a coin. Once a legitimate coin is found, it is recorded into the blockchain ledger. The miner is the first owner of the coin. In some networks, a fee is paid to the miner when a transaction is made using the coin.

- $\quad$ Traders purchase existing coins. They keep these coins for investment purposes or use them to buy and sell goods and services. Usually, traders use online wallets or exchanges to perform such activities.

\section{DATA AND METHODOLOGY}

This study is constructed based on the preliminary study of Komşuoğlu Yılmaz and Boydaş Hazar (2018) which is presented in the proceedings book of Istanbul Finance Congress, 2018. In this study, conjoint analysis has been conducted. Conjoint method is a statistical analysis method and by using this method researchers determine the value of the attributes of a product or a feature for its consumers. Conjoint analysis is a method for analyzing preferences of customers; it is a useful tool for predicting and determining responses of customers to new product features and totally new products.

In conjoint analysis, main principles are (1) segmenting an asset into its attributes and (2) choosing preference levels for each of these attributes of the chosen asset. In this study five attributes have been determined. These attributes are 
profitability, convenience, anonymity, security and bookkeeping. After determining attributes, possible levels of each attributes have been determined.

These attributes and their levels determined for the study can be seen in Table 1 below:

Table 1: Attributes and Levels

\begin{tabular}{llllll}
\hline Attributes & & \multicolumn{4}{c}{ Levels } \\
\hline Profitability & Very high & High & Moderate & Low & Break-even \\
\hline Convenience & Very easy & Easy & Moderate & Difficult & Very difficult \\
\hline Anonymity & Anonymity & $\begin{array}{l}\text { Pseudonymity } \\
\text { with difficulty }\end{array}$ & Pseudonymity & Linkability with \\
& & High & Moderate & Low & Linkability \\
\hline Security & Impossible & Manageable & Some confusion & Inadequate standards & Inapplicable \\
\hline Bookkeeping & All clear & & &
\end{tabular}

Profitability

In this study attribute "profitability" is related to how much the investor wants to gain on the investment. The amount that the investor profits, is the difference between the current market price and the investor's purchase price of the cryptocurrency. The gap between the market and the purchase price determines the level of profitability. If this gap is larger, the profitability is higher.

The explanation on attribute "profitability" and its related levels can be seen in Table 2 below:

Table 2: Definition of Attribute "Profitability" and its Levels

\begin{tabular}{|c|c|c|c|c|c|}
\hline Attribute & & & Levels & & \\
\hline Profitability & $\begin{array}{l}\text { Very High: } \\
\text { The investor } \\
\text { wants returns } \\
\text { very high } \\
\text { compared to } \\
\text { other investment } \\
\text { opportunities at } \\
\text { all times. Even a } \\
\text { slight drop in } \\
\text { earnings will not } \\
\text { be tolerated. }\end{array}$ & $\begin{array}{l}\text { High: } \\
\text { The investor } \\
\text { expects high } \\
\text { returns compared } \\
\text { to other } \\
\text { investment } \\
\text { possibilities but } \\
\text { accepts some } \\
\text { losses as long as } \\
\text { the value of the } \\
\text { cryptocurrency } \\
\text { recovers quickly. }\end{array}$ & $\begin{array}{l}\text { Moderate: } \\
\text { The investor expects slightly } \\
\text { high returns compared to } \\
\text { other investment } \\
\text { possibilities over a period of } \\
\text { time. The value of the } \\
\text { cryptocurrency is expected } \\
\text { to decline at certain times, } \\
\text { but it is expected to recover } \\
\text { over some time. }\end{array}$ & $\begin{array}{l}\text { Low: } \\
\text { The earnings } \\
\text { do not have } \\
\text { to beat } \\
\text { alternative } \\
\text { investments } \\
\text { as long as } \\
\text { there is some } \\
\text { gain. }\end{array}$ & $\begin{array}{l}\text { Break-Even: } \\
\text { The investor } \\
\text { does not } \\
\text { initially } \\
\text { require high } \\
\text { earnings. He } \\
\text { would be } \\
\text { satisfied as } \\
\text { long as he } \\
\text { does not lose } \\
\text { money. }\end{array}$ \\
\hline
\end{tabular}

\section{Convenience}

In this study attribute convenience is related to how easy it is to exchange fiat currency to coins, and vice versa. Fiat currency is money which is backed by a legal government. US Dollars, Euros are fiat currency examples. Investors have to exchange their fiat money to purchase cryptocurrencies. If they want to get out of the cryptocurrency market, they have to sell their coins for fiat money. If investors frequently need to exchange fiat currency and coins, they need to conveniently find exchanges which would carry this transaction.

The explanation on attribute "convenience" and its related levels can be seen in Table 3 below:

Table 3: Definition of Attribute "Convenience" and its Levels

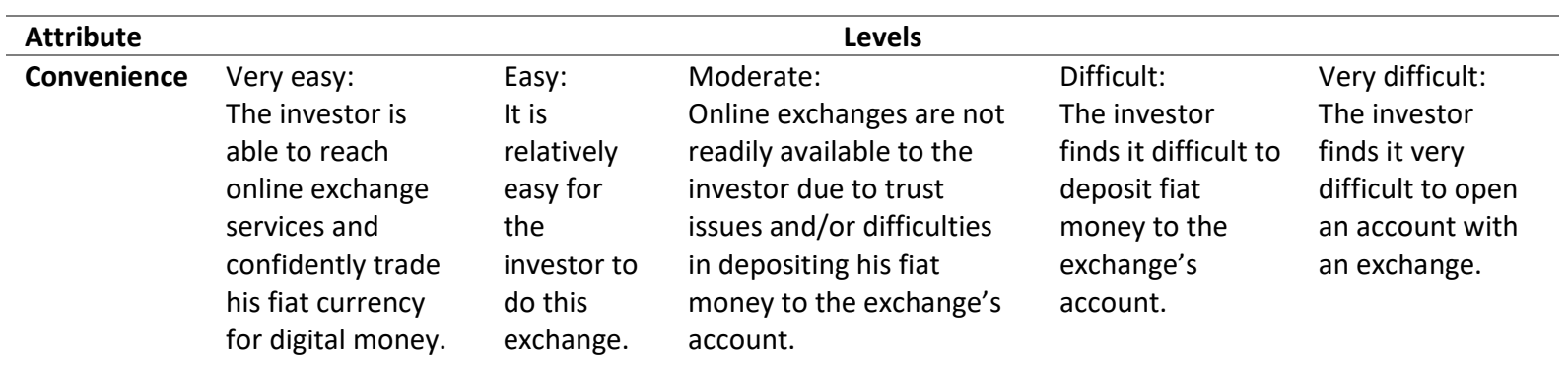




\section{Anonymity}

In this study attribute "anonymity" is related to how much the investor wants to keep his cryptocurrency transactions private. Anonymity refers to the concept of unlinkability (Pfitzman and Hansen, 2005) of coins to transactions and to real world identities. If the investor's public key is linked to transactions with which he signs those transactions but not to his real-world name, it is called pseudonymity. If the investor wants to keep his real-world name and his transactions with his coins secret, then it is safe to say that anonymity is important to him. If the investor does not object to the fact that public may relate the coins to the transactions as long as his real name is not revealed, he is satisfied with pseudonymity. If privacy is not important for the investor, he would be indifferent to linkability of his coins to both the related transactions and to his real-world name.

The explanation on attribute "anonymity" and its related levels can be seen in Table 4 below:

Table 4: Definition of Attribute "Anonymity" and its Levels

\begin{tabular}{|c|c|c|c|c|c|}
\hline Attribute & & & Levels & & \\
\hline Anonymity & $\begin{array}{l}\text { Anonymity: } \\
\text { Privacy is very } \\
\text { important for the } \\
\text { investor, so that he } \\
\text { requires full } \\
\text { anonymity. The } \\
\text { cryptocurrencies } \\
\text { that he owns } \\
\text { should not be } \\
\text { linked to their } \\
\text { transaction history } \\
\text { or to his real } \\
\text { identity. }\end{array}$ & $\begin{array}{l}\text { Pseudonymity with } \\
\text { difficulty: } \\
\text { Privacy is important for } \\
\text { the investor. He does } \\
\text { not want to share the } \\
\text { transaction history of } \\
\text { his cryptocurrencies } \\
\text { with public. However, } \\
\text { he would not mind if } \\
\text { regulatory bodies relate } \\
\text { his public key to } \\
\text { transactions using high } \\
\text { technology. }\end{array}$ & $\begin{array}{l}\text { Pseudonymity: } \\
\text { The investor } \\
\text { does not mind } \\
\text { if the } \\
\text { transaction } \\
\text { history of his } \\
\text { coins is a } \\
\text { public } \\
\text { knowledge as } \\
\text { long as his } \\
\text { real-world } \\
\text { identity is not } \\
\text { revealed. }\end{array}$ & $\begin{array}{l}\text { Linkability with } \\
\text { difficulty: } \\
\text { The investor is } \\
\text { indifferent that } \\
\text { the transaction } \\
\text { history may be } \\
\text { linked to his real } \\
\text { identity by those } \\
\text { who have the } \\
\text { technology, such } \\
\text { as regulatory } \\
\text { bodies of the } \\
\text { state. }\end{array}$ & $\begin{array}{l}\text { Linkability: } \\
\text { Privacy is not } \\
\text { important for the } \\
\text { investor. He is } \\
\text { indifferent to } \\
\text { linkability of his } \\
\text { coins both to the } \\
\text { related } \\
\text { transactions and } \\
\text { to his real-world } \\
\text { name. }\end{array}$ \\
\hline
\end{tabular}

\section{Security}

Cryptocurrencies are created, used and stored in the virtual world. The major problem of assets of the virtual world is that the network may be hacked, and the coins may be stolen. If the investor has confidence that the network cannot be hacked, and his coins are safe, he would be eager to invest in cryptocurrencies. However, the question is if he feels that the network is prone to hacking and his coins may be lost in the process, will he still be willing to invest in cryptocurrencies.

The explanation on attribute "security" and its related levels can be seen in Table 5 below:

Table 5: Definition of Attribute "Security" and its Levels

\begin{tabular}{|c|c|c|c|c|c|}
\hline $\begin{array}{l}\text { Attribute } \\
\text { Security }\end{array}$ & \multicolumn{5}{|c|}{ Levels } \\
\hline Security & $\begin{array}{l}\text { Impossible: } \\
\text { The investor is } \\
\text { confident that } \\
\text { the network } \\
\text { and its } \\
\text { protocols } \\
\text { cannot be } \\
\text { breached, and } \\
\text { his coins } \\
\text { cannot be } \\
\text { stolen. }\end{array}$ & $\begin{array}{l}\text { High: } \\
\text { The investor is } \\
\text { confident of the } \\
\text { network } \\
\text { security; } \\
\text { however, he } \\
\text { accepts that } \\
\text { some risks exist } \\
\text { related to the } \\
\text { online } \\
\text { exchanges. }\end{array}$ & $\begin{array}{l}\text { Moderate: } \\
\text { The investor } \\
\text { accepts the security } \\
\text { problems of the } \\
\text { cyber-world. } \\
\text { However, he thinks } \\
\text { he can overcome } \\
\text { this problem by } \\
\text { being careful in } \\
\text { choosing the } \\
\text { services he uses. }\end{array}$ & $\begin{array}{l}\text { Low: } \\
\text { This attribute is related } \\
\text { to the investor's } \\
\text { perception of the } \\
\text { difficulty that his coins } \\
\text { might be stolen. Since } \\
\text { the digital money is } \\
\text { merely an address in the } \\
\text { cyber-world, it is } \\
\text { possible to hack or steal } \\
\text { it electronically. }\end{array}$ & $\begin{array}{l}\text { Easy: } \\
\text { The investor } \\
\text { accepts the } \\
\text { possibility of his } \\
\text { coins to be stolen } \\
\text { in the cyber-world. }\end{array}$ \\
\hline
\end{tabular}

\section{Bookkeeping}

Attribute "bookkeeping" is related to the ambiguity in accounting treatments of cryptocurrencies. Cryptocurrencies are a new asset class. There is currently no consensus on accounting standards and taxation regulations. Recording transactions related to digital money is especially important for institutional investors. When a company converts its fiat money to digital money for investment purposes, it has to record this transaction and pay taxes if the cryptocurrency appreciates.

The explanation on attribute "bookkeeping" and its related levels can be seen in Table 6 below: 
Table 6: Definition of Attribute "Bookkeeping" and its Levels

\begin{tabular}{|c|c|c|c|c|c|}
\hline \multirow{2}{*}{$\begin{array}{l}\text { Attribute } \\
\text { Bookkeeping }\end{array}$} & \multicolumn{5}{|c|}{ Levels } \\
\hline & $\begin{array}{l}\text { All clear: } \\
\text { The investor has } \\
\text { knowledge on how } \\
\text { to record } \\
\text { transactions related } \\
\text { to cryptocurrencies. } \\
\text { He finds all } \\
\text { regulations related } \\
\text { to bookkeeping and } \\
\text { taxation are clearly } \\
\text { defined. }\end{array}$ & $\begin{array}{l}\text { Manageable: } \\
\text { The investor } \\
\text { is clear which } \\
\text { accounting } \\
\text { standard } \\
\text { applies. }\end{array}$ & $\begin{array}{l}\text { Some confusion: } \\
\text { The investor is not } \\
\text { clear about all the } \\
\text { standards and } \\
\text { regulations related to } \\
\text { accounting, however, } \\
\text { he finds such issues } \\
\text { manageable and has } \\
\text { a plausible } \\
\text { bookkeeping system. }\end{array}$ & $\begin{array}{l}\text { Inadequate } \\
\text { standards: } \\
\text { The investor is } \\
\text { not clear which } \\
\text { accounting } \\
\text { standard } \\
\text { applies. He } \\
\text { thinks his } \\
\text { bookkeeping is } \\
\text { inadequate and } \\
\text { troublesome. }\end{array}$ & $\begin{array}{l}\text { Inapplicable: } \\
\text { The investor feels } \\
\text { that laws and } \\
\text { regulations } \\
\text { governing } \\
\text { cryptocurrency } \\
\text { bookkeeping is so } \\
\text { unclear and } \\
\text { confusing that his } \\
\text { bookkeeping system } \\
\text { will not satisfy any } \\
\text { audit. }\end{array}$ \\
\hline
\end{tabular}

\section{FINDINGS AND DISCUSSIONS}

In this research, 25 conjoint cards (bundles) have been created by using orthogonal design and distributed to the participants who have been selected by using convenience sampling method. Because of the nature of the population (people with necessary level of information on cryptocurrencies), sampling size in our study is limited to 101 participants.

Bundles are listed below in Table 8:

Table 8: Conjoint Analysis Bundles

\begin{tabular}{|c|c|c|c|c|c|}
\hline $\begin{array}{l}\text { ATTRIBUTES/ } \\
\text { BUNDLES }\end{array}$ & BUNDLE 1 & BUNDLE 2 & BUNDLE 3 & BUNDLE 4 & BUNDLE 5 \\
\hline Profitability & Very High & Very High & Very High & Very High & Very High \\
\hline Convenience & Very Easy & Easy & Moderate & Difficult & Very Difficult \\
\hline Anonimity & Anonimity & $\begin{array}{l}\text { Pseudonymity with } \\
\text { difficulty }\end{array}$ & Pseudonymity & $\begin{array}{l}\text { Linkability with } \\
\text { difficulty }\end{array}$ & Linkability \\
\hline Security & Impossible & Moderate & Easy & High & Low \\
\hline Bookkeeping & All Clear & $\begin{array}{l}\text { Inadequate } \\
\text { standards }\end{array}$ & Manageable & Inapplicable & Some Confusion \\
\hline $\begin{array}{l}\text { ATTRIBUTES/ } \\
\text { BUNDLES }\end{array}$ & BUNDLE 6 & BUNDLE 7 & BUNDLE 8 & BUNDLE 9 & BUNDLE 10 \\
\hline Profitability & High & High & High & High & High \\
\hline Convenience & Very Easy & Easy & Moderate & Difficult & Very Difficult \\
\hline Anonimity & $\begin{array}{l}\text { Pseudonymity with } \\
\text { difficulty }\end{array}$ & Pseudonymity & $\begin{array}{l}\text { Linkability with } \\
\text { difficulty }\end{array}$ & Linkability & Anonimity \\
\hline Security & High & Low & Impossible & Moderate & Easy \\
\hline Bookkeeping & Manageable & Inapplicable & Some Confusion & All Clear & $\begin{array}{l}\text { Inadequate } \\
\text { standards }\end{array}$ \\
\hline $\begin{array}{l}\text { ATTRIBUTES/ } \\
\text { BUNDLES }\end{array}$ & BUNDLE 11 & BUNDLE 12 & BUNDLE 13 & BUNDLE 14 & BUNDLE 15 \\
\hline Profitability & Moderate & Moderate & Moderate & Moderate & Moderate \\
\hline Convenience & Very Easy & Easy & Moderate & Difficult & Very Difficult \\
\hline Anonimity & Pseudonymity & $\begin{array}{l}\text { Linkability with } \\
\text { difficulty }\end{array}$ & Linkability & Anonimity & $\begin{array}{c}\text { Pseudonymity with } \\
\text { difficulty }\end{array}$ \\
\hline Security & Moderate & Easy & High & Low & Impossible \\
\hline Bookkeeping & Some Confusion & All Clear & $\begin{array}{l}\text { Inadequate } \\
\text { standards }\end{array}$ & Manageable & Inapplicable \\
\hline $\begin{array}{l}\text { ATTRIBUTES/ } \\
\text { BUNDLES }\end{array}$ & BUNDLE 16 & BUNDLE 17 & BUNDLE 18 & BUNDLE 19 & BUNDLE 20 \\
\hline Profitability & Low & Low & Low & Low & Low \\
\hline Convenience & Very Easy & Easy & Moderate & Difficult & Very Difficult \\
\hline Anonimity & $\begin{array}{l}\text { Linkability with } \\
\text { difficulty }\end{array}$ & Linkability & Anonimity & $\begin{array}{l}\text { Pseudonymity with } \\
\text { difficulty }\end{array}$ & Pseudonymity \\
\hline Security & Low & Impossible & Moderate & Easy & High \\
\hline Bookkeeping & $\begin{array}{l}\text { Inadequate } \\
\text { standards }\end{array}$ & Manageable & Inapplicable & Some Confusion & All Clear \\
\hline ATTRIBUTES/ & BUNDLE 21 & BUNDLE 22 & BUNDLE 23 & BUNDLE 24 & BUNDLE 25 \\
\hline
\end{tabular}




\begin{tabular}{|c|c|c|c|c|c|}
\hline BUNDLES & & & & & \\
\hline Profitability & Break-Even & Break-Even & Break-Even & Break-Even & Break-Even \\
\hline Convenience & Very Easy & Easy & Moderate & Difficult & Very Difficult \\
\hline Anonimity & Linkability & Anonimity & $\begin{array}{c}\text { Pseudonymity with } \\
\text { difficulty }\end{array}$ & Pseudonymity & $\begin{array}{c}\text { Linkability with } \\
\text { difficulty }\end{array}$ \\
\hline Security & Easy & High & Low & Impossible & Moderate \\
\hline Bookkeeping & Inapplicable & Some Confusion & All Clear & $\begin{array}{l}\text { Inadequate } \\
\text { standards }\end{array}$ & Manageable \\
\hline
\end{tabular}

On the other side of the bundles, there was a five-question demographic survey which includes questions on age, gender, income, marital status and education.

Demographic distribution of the participants can be seen in Table 7 below:

Table 7: Demographic Distribution of the Participants

\begin{tabular}{|c|c|c|c|}
\hline $\begin{array}{l}\text { Demographic } \\
\text { Variable }\end{array}$ & Choices & Frequency & Percentage \\
\hline \multirow[t]{2}{*}{ Gender } & Male & 74 & 73.3 \\
\hline & Female & 27 & 26.7 \\
\hline \multirow[t]{4}{*}{ Age } & $18-24$ & 60 & 59.4 \\
\hline & $25-34$ & 36 & 35.6 \\
\hline & $35-44$ & 4 & 4 \\
\hline & $45-54$ & 1 & 1 \\
\hline \multirow[t]{3}{*}{ Education } & Bachelors & 50 & 49.5 \\
\hline & Masters & 49 & 48.5 \\
\hline & PhD & 2 & 2 \\
\hline \multirow[t]{4}{*}{ Income } & $0-1500 \mathrm{TL}$ & 20 & 19.80 \\
\hline & $1500-4000 \mathrm{TL}$ & 65 & 64.3 \\
\hline & $4000-8000 \mathrm{TL}$ & 10 & 9.9 \\
\hline & $8000+T L$ & 6 & 5.9 \\
\hline \multirow[t]{3}{*}{ Marital Status } & Single & 71 & 70.3 \\
\hline & Married & 22 & 21.8 \\
\hline & Not Specified & 8 & 9 \\
\hline
\end{tabular}

Participants were asked to rank the 25 cards from the best to the worst. Data collected by ranking bundles have been transformed to preference points between 100 (most preferable) to 0 (least preferable) and analyzed by using Marketing Engineering for Excel software. Marketing Engineering for Excel is software especially designed to analyze marketing research problems.

As a first step, respondents' preference partworths have been created by using the software. In partworths table, as a convention, the least preferred level of each attribute gets set to 0 for all respondents and the sum of the most preferred levels of all attributes is equal to 100 . The importance of an attribute equals the value of the most preferred level for that attribute (Conjoint Tutorial, 2018)

In conjoint analysis, respondents' preference partworths table provides a combined review of all respondents, attributes, levels and their values for respondents. Results obtained at this stage indicate that the most important attribute for most of the respondents is profitability and for $61 \%$ of them, the most important factor to consider when they make cryptocurrency choice is very high and high level of profitability. Second and third important attributes are bookkeeping and security. Least important attributes are convenience and anonymity.

After creating respondents' preference partworths, to be able to conduct further analysis, current situation in the market is simulated by creating two current product options. Since there are many types of altcoins in the market it has been created only one profile for all of them under the name of Altcoin. These current situations are simulated by researchers considering real attributes of bitcoin and altcoins.

These profiles can be seen in Table 9 below: 
Table 9: Profiles in Current Situation

\begin{tabular}{lll}
\hline Attributes / Existing Product Profiles & Bitcoin & Altcoins \\
\hline Profitability & Low & Moderate \\
\hline Convenience & Difficult & Moderate \\
\hline Anonymity & Pseudonymity with difficulty & Pseudonymity with difficulty \\
\hline Security & Low & Low \\
\hline Bookkeeping & Inadequate standards & Inapplicable \\
\hline
\end{tabular}

And as new product profiles, two options have been created: Best product and Worst Product. For both of them, least preferable levels of attributes have been chosen.

In table 10, these options can be seen:

Table 10: Profiles with Best and Worst Options

\begin{tabular}{lll}
\hline Attributes / Existing Product Profiles & Best Option & Worst Option \\
\hline Profitability & Very High & Break-Even \\
\hline Convenience & Very Easy & Very Difficult \\
\hline Anonymity & Anonymity & Linkability \\
\hline Security & Impossible & Easy \\
\hline Bookkeeping & All Clear & Inapplicable \\
\hline
\end{tabular}

The most prominent cryptocurrency option in the market is Bitcoin with its $48 \%$ market share. The total market share of other more than $2000^{1}$ different altcoins are $52 \%$. Research results indicate that product "best option" may have $60 \%$ of market share and may create a cannibalization effect especially on Bitcoin. This result suggests that a defective cryptocurrency alternative can have a cannibalization effect on bitcoin.

Market share simulation made by Marketing Engineering software for "Best Option" can be seen in Figure 1 below:

Figure 1: Market Share Simulation for New Product Profile "Best Option"

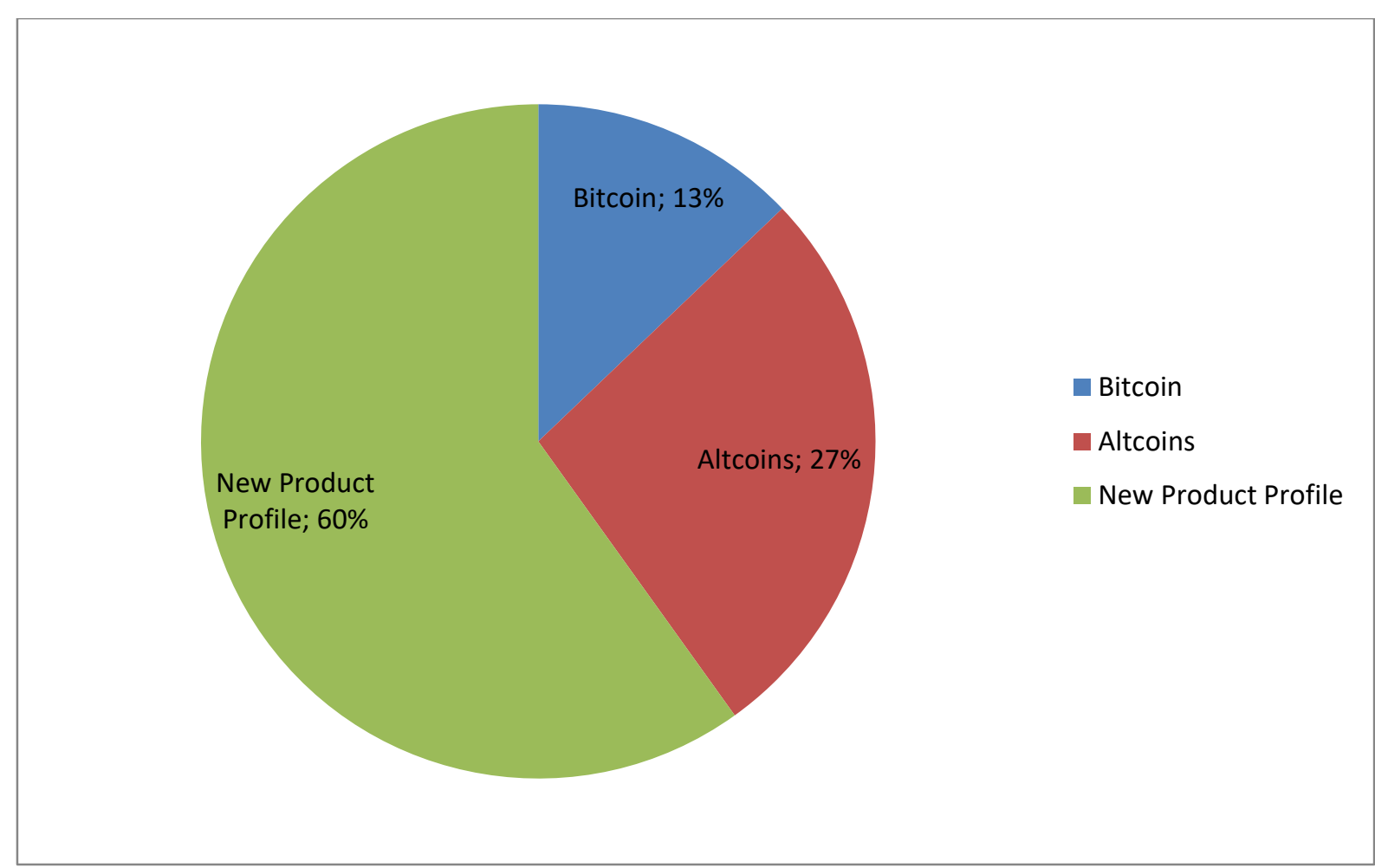

${ }^{1}$ There are 2075 altcoin types in the market at 29 November 2018 listed on coinmarketmap.com 
In the worst-case scenario a new cryptocurrency type with all worst levels is introduced in the market. The results of the market prediction with this alternative is dramatically different. New product profile market share decreased to 12 percent.

\section{CONCLUSION}

Academic researchers and industrial practitioners widely supported almost for 50 years, and this shows the potential of the conjoint method in providing a useful way to represent consumer preferences and the ability to predict the behavior of the consumer towards new stimuli (Green \& Srinivasan, 1978). In the literature many studies have examined factors affecting investor decisions with a consumer behavior perspective.

Today, the importance of crypto currencies is increasing day by day and new currencies take their place in the market. Bitcoin, a long-standing crypto currency player, faces competitors who are more powerful than bitcoin. In this study, the attributes of the new currencies have been prioritized in order to obtain a competitive advantage in the crypto-currency market.

Investor behavior varies according to the characteristics of investment instruments. In this study, investor behavior in purchasing cryptocurrencies is set forth using conjoint analysis technique. Five attributes with five levels each are chosen. It is predicted that these attributes are the most important indicators of investor behavior. The importance of this study is the first study using conjoint analysis to determine the most important factors and their levels influencing cryptocurrency investment decisions.

Not surprisingly, most important attribute for most of the investors or future investors is "Profitability". This study confirms that the majority of investors have high profit expectation from crypto currencies. But study results also include some unexpected findings. Anonymity is not one of the main concerns for investors and almost equal number of investors prefers very high and very low level of bookkeeping.

The main limitation of this study is the hypothetical bundles which cannot be found in the real time situations. Cryptocurrency developers should make an effort in developing coins which have features that are preferred by investors. In future studies, hypothetical bundles can be tested in market share simulations by using conjoint analysis.

\section{REFERENCES}

Atzei, N., Bartoletti, M., \& Cimoli, T. (2017). A survey of attacks on Ethereum smart contracts (SoK). In Lecture Notes in Computer Science (including subseries Lecture Notes in Artificial Intelligence and Lecture Notes in Bioinformatics). http://doi.org/10.1007/978-3-662-54455$6 \_8$

Aung, Y. N., \& Tantidham, T. (2018). Review of Ethereum: Smart home case study. In Proceeding of 2017 2nd International Conference on Information Technology, INCIT 2017. http://doi.org/10.1109/INCIT.2017.8257877

Bonneau, J., Miller, A., Clark, J., Narayanan, A., Kroll, J. A., \& Felten, E. W. (2015). SoK: Research perspectives and challenges for bitcoin and cryptocurrencies. In Proceedings - IEEE Symposium on Security and Privacy. http://doi.org/10.1109/SP.2015.14

Buterin, V. (2014). A Next-Generation Smart Contract and Decentralized Application Platform - Ethereum White Paper. Ethereum Project White Paper.

Chohan, U. (2017). Cryptocurrencies: A Brief Thematic Review. SSRN.

Conjoint Tutorial. (2018) Marketing Engineering for Excel Software

Corbet, S., Lucey, B., \& Yarovaya, L. (2018). Datestamping the Bitcoin and Ethereum bubbles. Finance Research Letters. http://doi.org/10.1016/j.frl.2017.12.006

Dourado, E., \& Brito, J. (2014). Cryptocurrency. The New Palgrave Dictionary of Economics. http://doi.org/10.1057/10.1057/9780230226203.3924

Elbahrawy, A., Alessandretti, L., Kandler, A., Pastor-Satorras, R., \& Baronchelli, A. (2017). Evolutionary dynamics of the cryptocurrency market. Royal Society Open Science. http://doi.org/10.1098/rsos.170623

Glaser, F., \& Bezzenberger, L. (2015). Beyond Cryptocurrencies - A Taxonomy Of Decentralized Consensus. ECIS. http://doi.org/10.18151/7217326

Green, P. E., \& Srinivasan, V. (1978). Conjoint Analysis in Consumer Research: Issues and Outlook. Journal of Consumer Research. http://doi.org/10.1086/208721

Hacked.com (2018), www.hacked.com, (22.10.2018) 
Iansiti, M., Lakhani, K. R., ethereum, Ethereum community, Kugler, L., Tapscott, A., \& Tapscott, D. (2017). What is Ethereum? - Ethereum Homestead 0.1 documentation. Harvard Buisness Review. http://doi.org/10.1016/j.annals.2005.11.001

Iwamura, M., Kitamura, Y., \& Matsumoto, T. (2014). Is Bitcoin the Only Cryptocurrency in the Town? Economics of Cryptocurrency And Friedrich A. Hayek. SSRN.

Jiang, Z., \& Liang, J. (2016). Cryptocurrency Portfolio Management with Deep Reinforcement Learning. ArXiv.

Komşuoğlu Yılmaz, Nurgün, Boydaş Hazar, Hülya (2018). Determining the Factors Affecting Investors' Decision-Making Process in Cryptocurrency Investments, Istanbul Finance Congress, November 1-2, 2018, Istanbul, Turkey.

Lee, D. K. C., Guo, L., \& Wang, Y. (2018). Cryptocurrency: A new investment opportunity? Journal of Alternative Investments. http://doi.org/10.3905/jai.2018.20.3.016

Leising, M., \& Robinson, E. (2018). Ripple Wants XRP to Be Bitcoin for Banks. If Only the Banks Wanted It. Bloomberg.

Nakamoto, S. (2008). Bitcoin: A Peer-to-Peer Electronic Cash System. Www.Bitcoin.Org. http://doi.org/10.1007/s10838-008-9062-0

Ong, B., Lee, T. M., Li, G., \& Chuen, D. L. K. (2015). Chapter 5 - Evaluating the Potential of Alternative Cryptocurrencies. Handbook of Digital Currency. http://doi.org/10.1016/B978-0-12-802117-0.00005-9

Pfitzmann, A., \& Marit Hanse. (2008). Anonymity, Unlinkability, Unobservability, Pseudonymity, and Identity Management - A Consolidated Proposal for Terminology. Journal of Chemical Information and Modeling, 148(9), 164-179. https://doi.org/10.1017/CBO9781107415324.004

Phillip, A., Chan, J., \& Peiris, S. (2018). A new look at Cryptocurrencies. Economics Letters. http://doi.org/10.1016/j.econlet.2017.11.020

Pustišek, M., \& Kos, A. (2018). Approaches to Front-End loT Application Development for the Ethereum Blockchain. In Procedia Computer Science. http://doi.org/10.1016/j.procs.2018.03.017

Puthal, D., Malik, N., Mohanty, S. P., Kougianos, E., \& Das, G. (2018). Everything You Wanted to Know about the Blockchain: Its Promise, Components, Processes, and Problems. IEEE Consumer Electronics Magazine, 7(4), 6-14. https://doi.org/10.1109/MCE.2018.2816299

Schwartz, D., Youngs, N., \& Britto, A. (2014). The Ripple protocol consensus algorithm. Ripple Labs Inc White Paper.

Sompolinsky, Y., \& Zohar, A. (2013). Accelerating Bitcoin's Transaction Processing. Fast Money Grows on Trees, Not Chains. IACR Cryptology EPrint Archive.

Stellar News, https://cointelegraph.com/tags/stellar, (26.11.2018)

Stellar.org, https://www.stellar.org/, (26.11.2018)

Wikipedia, What is Cryptocurrency, https://en.wikipedia.org/wiki/Cryptocurrency, (26.11.2018)

What is EOS, https://coincentral.com/what-is-eos, (26.11.2018)

White, L. H. (2015). The market for cryptocurrencies. Cato Journal. http://doi.org/10.2139/ssrn.2538290

Wood, G. (2014). Ethereum: a secure decentralised generalised transaction ledger. Ethereum Project Yellow Paper. http://doi.org/10.1017/СBO9781107415324.004

Yli-Huumo, J., Ko, D., Choi, S., Park, S., \& Smolander, K. (2016). Where is current research on Blockchain technology? - A systematic review. PLoS ONE. http://doi.org/10.1371/journal.pone.0163477 